\title{
Avaliação da atividade de Casearia sylvestris Swartz (Flacourtiaceae) sobre os níveis séricos de triglicerídeos em ratos
}

\author{
Almeci L. B Werle, ${ }^{*, 1}$ Gilberto D. Zanetti,, Carla S. Ceron, ${ }^{2}$ Melânia P. Manfron ${ }^{2}$ \\ ${ }^{1}$ Multilab Ind e Com de Produtos Farmacêuticos, RS 401 Km 30 n 1009, 96700-000 \\ São Jerônimo-RS, Brasil, \\ ${ }^{2}$ Departamento de Farmácia Industrial, Universidade Federal de Santa Maria, Av. Roraima, S/N, Camobi \\ 97105-340 Santa Maria-RS, Brasil
}

\begin{abstract}
RESUMO: Esse trabalho teve como objetivo a avaliação da atividade do extrato aquoso e hidroalcoólico das folhas de Casearia sylvestris Swartz sobre os níveis séricos de triglicerídeos em ratos Wistar. Um dos usos populares dessa planta é como emagrecedor. As análises foram efetuadas após administração via oral de suspensão dos extratos em carboximetilcelulose $0,5 \%$ (CMC $0,5 \%$ ) na dose de $500 \mathrm{mg} / \mathrm{kg}$. Os valores obtidos comparados com os do grupo controle que recebeu apenas CMC $0,5 \%$. Os resultados obtidos mostram que o extrato hidroalcoólico de C. sylvestris baixa os níveis de triglicerídeos sanguíneos.
\end{abstract}

Unitermos: Casearia sylvestris, chá-de-bugre, triglicerídeos, Flacourtiaceae.

\begin{abstract}
Evaluation of the activity of Casearia sylvestris Swartz (Flacourtiaceae) on rats serum triglyceride". The aim of this work was to evaluate the activities of the aqueous and hydroalcoholic extracts of Casearia sylvestris leaves on Wistar rats serum triglyceride levels. One of the popular uses of this plant is on weight loss. The analyses have been done after administering suspension of extracts in carboxymethylcellulose $0.5 \%$ (CMC $0.5 \%), 500 \mathrm{mg} / \mathrm{kg}$ orally. The values obtained have been compared with the control group which only received CMC $0.5 \%$. The results have shown that the hydroalcoholic extract of $C$. sylvestris lowers the blood triglycerides.
\end{abstract}

Keywords: Casearia sylvestris, “chá-de-bugre”, triglycerides, Flacourtiaceae.

\section{INTRODUÇ̃̃O}

Casearia sylvestris Sw. (Flacourtiaceae,) é uma planta lenhosa, arbustiva ou arbórea, com folhas inteiras, de disposição alterna, em geral dística, com estípulas caducas encontrada especialmente nas regiões tropicais da América do Sul. (Joly, 1993).

No Brasil é conhecida popularmente como Guaçatonga, Porangaba e Chá de Bugre, e suas folhas são utilizadas na forma de chás como antiinflamatórias, depurativas, anti-reumáticas, mordida de cobra e vem sendo atualmente utilizada também para redução de peso. Pesquisas com C. sylvestris, tem relacionado a fitoquímica com suas ações farmacológicas, principalmente das folhas, tendo como base as suas indicações populares.

A presença de óleos essenciais foi detectada na droga seca em um teor de $0,12 \%$, com uma grande porcentagem de compostos sesquiterpênicos (Possolo e Ferreira, 1949). Silva e Bauer (1970) obtiveram por hidrodestilação das folhas frescas, o equivalente a $0,4 \%$ de óleo essencial, com elevada porcentagem de terpenos $(77,78 \%)$. Na desterpenação deste óleo encontrouse o ácido hexanóico $(0,58 \%)$, ácido este usado como matéria-prima na preparação de ésteres que servem de adjuvantes em composições odoríferas. Scavone (1970) detectaram a presença de flavonas, saponinas e óleo essencial - 2,1\% em relação à matéria seca, líquido amarelado, com odor semelhante ao do cedro e sabor não característico. Yamamoto (1995) e Luz (1998), em abordagem fitoquímica, evidenciaram a presença de taninos, flavonóides, saponinas e traços de alcalóides.

Silva (1929) descreve apenas a folha de $C$. sylvestris Swartz, por ser a parte oficializada como medicinal, sendo as principais características: epiderme glabra, formada de células poligonais, de paredes retas na face superior e levemente curvas na inferior, que é guarnecida de estomas envolvidos por células não diferenciadas. O mesofilo é heterogênio e assimétrico, formado na parte superior por várias camadas de células paliçádicas e na inferior por um parênquima de células ovais ou arredondadas, onde se observam, também, grandes bolsas secretoras. O sistema libero-lenhoso é representado por um cordão lenhoso, arqueado, recoberto sobre a face inferior por um líber mole que contém vários canais secretores e por um periciclo fibroso. A face superior do cordão é igualmente recoberta por um arco de periciclo mais ou menos lenhificado. $\mathrm{O}$ parênquima fundamental das nervuras encerra, também, numerosas bolsas secretoras.

Itokawa (1988) e Itokawa (1990) identificaram os tipos terpenóides encontrados nas folhas de $C$. 
sylvestris, associando suas atividades anti-tumorais. Constataram que a denominada casearina $\mathrm{C}$ apresentou boa tolerância citotóxica em cultivo celular, como também contra lesões tumorais tipo sarcoma em ratos. Foram isolados também casearinas A-F, chegando a descobrir ativos antitumorais. As estruturas foram totalmente elucidadas através de RMN 2D, espectroscópica circular, raios $\mathrm{X}$ e provas bioquímicas.

Ruppelt (1991) observou que várias plantas usadas popularmente como antiofídicas apresentam atividade antiinflamatória. A ação antiofifdica tem sido atribuída aos flavonóides presentes em diferentes espécies alcachofra, cainca, contra-erva, erva-debugre (folha e casca), guaco, jataí (folha e casca), manacá, paracarí e taiuiá. Todas apresentaram atividade analgésica e antiinflamatória com maior ou menor intensidade.

Basile (1990) estudaram, experimentalmente, as lesões gástricas em ratos na análise da atividade potencial das drogas antiúlcera. O extrato das folhas de C. sylvestris Swartz exerce uma significativa prevenção no teste do ligamento pilórico, com redução do volume de secreção gástrica e diminuição da secreção de ácido clorídrico. Uma vantagem da planta em relação às demais drogas testadas (cimetidina e misoprostol) é que o extrato da planta não modificou o $\mathrm{pH}$, não interferindo na atividade das pepsinas digestivas. O mecanismo de ação não foi definido. Estes autores ressaltam que C. sylvestris Swartz já é usada na medicina popular como antiúlcera, mas a natureza de seus compostos responsáveis por tal atividade não está definida.

Camargo (1995) usaram o extrato alcoólico de C. sylvestris Swartz, preparado por maceração de acordo com o processo A da primeira edição da Farmacopéia Brasileira, utilizando como solvente mistura de álcool e água na proporção de 2:1. Tal extrato foi utilizado no controle de manifestações de herpes simples com significativa redução de tempo dessas manifestações.

A possível atividade hipotrigliceridemiante das folhas de C. sylvestris despertou o interesse de avaliar tal atividade através da administração oral dos extratos da planta seguido da determinação dos níveis séricos de triglicerídeos.

\section{MATERIAL E MÉTODOS}

O material vegetal constitui-se de folhas de C. sylvestris Swartz cultivada no Jardim Botânico da UFSM e coletada em abril de 2000. A amostra testemunha (HSDB 10203) encontra-se depositada junto ao Herbário do Departamento de Biologia da UFSM. O material foi submetido à secagem em estufa com circulação de ar a $45-50{ }^{\circ} \mathrm{C}$ e triturada em moinho de facas tipo Willy e passado em tamis $0,86 \mu \mathrm{m}$.

Os extratos foram preparados por maceração utilizando como líquido extrator água destilada e etanol $70 \%$, para obtenção dos extratos, aquoso e hidroalcoólico, respectivamente. Em seguida os extratos foram filtrados e concentrados em evaporador rotativo e posteriormente suspensos em $\mathrm{CMC}$ a $0,5 \%$.

$\mathrm{O}$ experimento foi desenvolvido com ratos machos adultos da linhagem Wistar variedade Albina com peso entre 200-250 g. Os animais foram separados e distribuídos aleatoriamente em três grupos de 10 animais e que foram identificados, receberam água e dieta ad libitum. Um grupo de animais recebeu via oral $500 \mathrm{mg} / \mathrm{Kg}$ de peso corporal da suspensão do extrato aquoso, e outro grupo, de suspensão de extrato hidroalcoólico. O grupo controle recebeu apenas CMS $0,5 \%$. O experimento foi realizado durante 28 dias consecutivos e o peso individual dos animais foi registrado diariamente. Após vinte e quatro horas da ultima administração, os animais foram anestesiados com éter etílico, abertos na cavidade abdominal e coletadas amostras sanguíneas da aorta abdominal e foram analisadas para determinação dos níveis séricos de triglicerídeos.

Os resultados encontrados na dosagem bioquímica de triglicerídeos dos grupos tratados com o extrato aquoso e com o extrato hidroalcóolico, foram expressos em média aritmética e as diferenças entre os grupos foram determinadas por Análise de Variância (ANOVA).

\section{RESULTADOS E DISCUSSÃO}

Os resultados obtidos nos ensaios experimentais e sua análise estatística demonstraram a atividade biológica dos extratos aquosos e hiodroalcóolico de C. sylvestris $\mathrm{Sw}$. para um nível de significância de 5\%. Analisando a figura 1 que apresentam os níveis séricos de triglicerideos, observa-se que os animais que receberm a suspensão de extrato hidroalcoólico apresentaram uma redução significativa nos níveis séricos de triglicerideos, o que não foi observado nos que receberam a suspensão do o extrato hidroalcoólico.

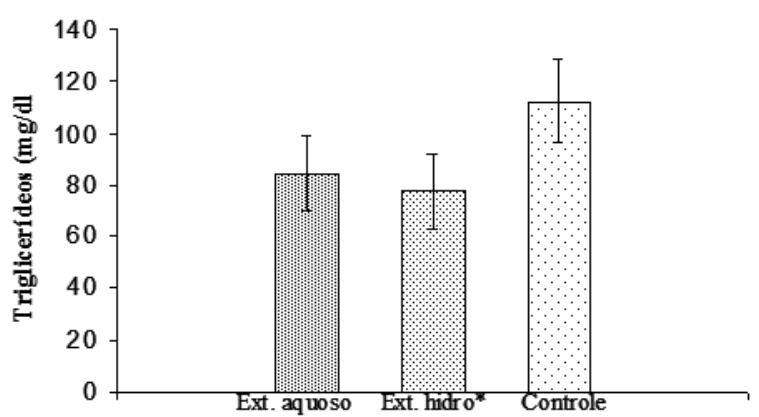

Figura 1. Dosagens sanguíneas de triglicerídeos para grupos tratados com $500 \mathrm{mg} / \mathrm{kg}$ de suspensão dos extratos aquoso e hidroalcóolico (hidro) de C. sylvestris em CMS 0,5\%. O grupo controle recebeu CMS 0,5\%. Asterisco denota diferença significante $(* \mathrm{p}<0,05)$ quando comparado com o controle. 
Ao analisar a diferença entre as médias dos efeitos do extrato hidroalcóolico e do controle por ANOVA, encontra-se uma diminuição dos níveis séricos de triglicerídeos significativa ao nível de 5\%, para o extrato hidroalcóolico. $\mathrm{O}$ extrato aquoso, não apresentou variação significativa quando analisado estatisticamente.

A literatura tem destacado várias atividades para a planta, algumas delas já comprovadas cientificamente, como seu efeito antiulcera (Basile et al., 1990), atividade antiinflamatória (Ruppelt et al., 1991) e a habilidade de inibir a atividade ATPasica da Pdr5p (Rangel et al., 2008), entretanto não foram encontrados estudos da ação da planta sobre os níveis de triglicerideos sanguíneos, apenas a medicina popular a indicava como hipotrigliceridemiante.

Os triglicerídeos são depósitos de combustível metabólico armazenados por células especializadas chamadas adipócitos, as quais formam o tecido adiposo em maior quantidade sob a pele, na cavidade abdominal e nas glândulas mamárias (Lehninger et al., 1995, ). A maior parte da estocagem de gordura no tecido adiposo e nas células musculares é na forma de triglicerídeos (Champe \& Harvey, 2000).

O aumento dos níveis séricos dos mesmos é um fator de risco independente para doenças cardiovasculares e há urgente necessidade de baixar os níveis de triglicerídeos no plasma, diminuindo assim o risco de doenças cardíacas (Austin et al., 1998).

\section{CONCLUSÃO}

Os resultados demonstram que extrato hidroalcóolico de C. sylvestris $\mathrm{Sw}$ apresentou atividade hipotrigliceridemiante em ratos machos adultos da linhagem Wistar, o que pode justificar o seu uso popular na redução de peso.

\section{REFERÊNCIAS}

Agra MF, França PF, Barbosa-Filho JM 2007. Synopsis of the plants known as medicinal and poisonous in Northeast of Brazil. Rev Bras Farmacogn 17: 114-140.

Agra MF, Silva KN, Basílio IJLD, França PF, Barbosa-Filho JM 2008. Survey of medicinal plants used in the region Northeast of Brazil. Rev Bras Farmacogn 18: 472508.

Austin MA, Hokanson JE, Edwards KL 1998. Hypertriglyceridemia as a cardiovascular risk factor. Am J Cardiol 81: 7B-12B.

Basile AC, Serie JAA, Panizza S, Oshiro TT, Azzolini CA 1990. Pharmacological assay of Casiaria sylvestris. I: preventive antiulcer activity an toxicity of the leave crude extract. J Ethnopharmacol 30: 185-197.

Camargo FG, Gomes E, Pannunzio E, Buenos VS 1993. Ação do extrato alcoólico de guaçatonga (Casearia sylvestris Swartz) em subcutâneo de camundongo. Parte I - Estudo histológico. Lecta 13: 47-48.

Champe PC, Harvey RA 2000. Bioquimica ilustrada. 2. ed.
Porto Alegre: Artes Medicas.

Itokawa $\mathrm{H}$, Totsuka $\mathrm{N}$, Takeya $\mathrm{K}$, Watanabe $\mathrm{K}$, Obata $\mathrm{E}$ 1988. Antitumor principles from C. sylvestris $\mathrm{Sw}$ Flacourtiaceae. Struture elucidation of new clerodane diterpenes by D NMR spectroscopy. Chem Pharm. Bull 36: 1585-1588.

Itokawa H, Totsuka N, Morita H, Takeya k, Itaka Y, Schenkel EP, Motidome M 1990. New antitumor principles, casearins A-F from C. sylvestris $\mathrm{Sw}$ (Flacourtiaceae). Chem Pharm. Bull 38: 3384-3387.

Joly A B 1993. Botânica: Introdução à taxonomia vegetal. São Paulo: Nacional.

Lehninger AL, Nelson DL, Cox MM 1995. Princípios de Bioquímica. $2^{\mathrm{a}}$ ed. São Paulo: Sarvier.

Luz SFB, Sato MEO, Duarte MR, Santos CAM 1998. Parâmetros para controle de qualidade de folhas de $C$. sylvestris SW. - guaçatunga. Rev Bras Farmacogn 7: $1-11$.

Possolo H, Ferreira C 1949. Saponinas e outros compostos interessantes na família das Flacourtiaceae. An Fac Farm Odont Univ São Paulo 7: 377-385.

Rangel LP, Abreu LF, Andrade AR, Leitão SG, Leitão GG, Ferreira-Pereira A 2008. Effect of different extracts from the Brazilian Atlantic Forest on the Pdr5p ATPase activity. Rev Bras Farmacogn 18: 30-36.

Ruppelt BM, Pereira EFRM, Gonçalves LC, Pereira NA 1991. Pharmacological screening of planta recommended by folk medicine as anti-snake venom. I. Analgesic and antiinflamatory activities. Mem Inst Oswaldo Cruz Rio de Janeiro 86: 203-205.

Scavone O, Grecchi R, Panniza S, Silva Rap S 1979. Guaçatonga (C. sylvestris Swartz) Aspectos botânicos da planta, ensaios fitoquímicos e propriedades cicatrizantes da folha. An Farm Quim São Paulo 19: 73-81.

Silva RAD 1929. Pharmacopeia dos Estados Unidos do Brasil. São Paulo: Nacional.

Silva GAA, Bauer L 1970. Análise do óleo essencial de $C$. sylvestris Sw-I. Rev Bras Farm 6: 328-331.

Yamamoto M M 1995. C. sylvestris Sw.: Aspectos botânicos, fitoquímicos e farmacológicos. Curitiba, 54p. Monografia - Curso de Especialização em Ciências Farmacêuticas - Produtos Naturais. Universidade Federal de Paraná. 